\title{
Rapid and efficient protocol to introduce exogenous DNA in Vibrio harveyi and Pseudoalteromonas sp.
}

\author{
Delavat François ${ }^{1,{ }^{*}}$, Bidault Adeline ${ }^{1}$, Pichereau Vianney ${ }^{1}$, Paillard Christine ${ }^{1}$
}

${ }^{1}$ Laboratoire des sciences de l'Environnement Marin, Institut Universitaire Européen de la Mer, Université de Bretagne Occidentale - UMR6539 CNRS/UBO/IRD/Ifremer, Plouzané, France

* Corresponding author : François Delavat, email address : francois.delavat@univ-brest.fr

\begin{abstract}
:
Vibrio campbellii BAA-1116 is renowned for its bioluminescence properties, and genetic tools are available to genetically track this strain. However, many other ecologically important $V$. harveyi strains exist, for which only few genetic tools are available. In this study, a rapid electroporation protocol was developed to transform replicative plasmids in various environmental $V$. harveyi and Pseudoalteromonas strains. Moreover, a mini-Tn7 delivery system was modified to site-specifically integrate mini-transposons in the genome of $V$. harveyi ORM4. As a proof-of-principle, replicative plasmids carrying bioreporters were introduced by electroporation in $V$. harveyi ORM4 cells, and gene expression was followed at the single cell level. We could demonstrate that a flagellar gene is subjected to bimodal gene expression in $V$. harveyi ORM4, being highly expressed in $10 \%$ of the population in stationary phase. This study extends the possibilities to study environmental Vibrio strains and uncovers the occurrence of phenotypic heterogeneity in flagellar expression in Vibrio.
\end{abstract}

Keywords: Electroporation, Mini-transposon, Vibrio harveyi, Pseudoalteromonas, phenotypic heterogeneity, Bioreporter, Flagellum expression 


\section{Introduction}

Bacteria from the genus Vibrio are commonly found in marine environments, either free living in the water column or associated with planktonic particles and animals. Many Vibrio strains are human pathogens, including Vibrio cholerae responsible for the deadly cholera disease, or Vibrio parahaemolyticus. However, other pathogenic Vibrio strains exist, including some infecting a wide range of marine organisms, from fish to marine invertebrates (shrimp, molluscs). Among them, one can cite Vibrio alginolyticus, Vibrio aestuarianus or Vibrio tapetis. Finally, even though the Vibrio harveyi type strain BAA-1116 (recently reclassified as Vibrio campbellii (Lin et al., 2010)) has been extensively studied for its quorum sensing and bioluminescence systems (Plener et al., 2015), other strains belonging to this species are known to be pathogens of fish, shrimps and molluscs (Austin \& Zhang, 2006). Interestingly, while the host spectrum of this species is very broad, colonization is hostspecific, with a single strain of $V$. harveyi being able to infect a limited group of hosts. This is the case for $V$. harveyi ORM4 which specifically infects the European abalone Haliotis tuberculata (Nicolas et al., 2002). V. harveyi ORM4 was isolated in 2002 after a severe outbreak which resulted in the mortality of $50 \%$ to $90 \%$ of the natural European abalone stock in Brittany and Normandy (France) in the late 90's (Nicolas et al., 2002). V. harveyi ORM4 is also able to provoke abalone mortality in laboratory experiments, with $70 \%$ to $90 \%$ of death occurring within 3 days post-infection (Travers et al., 2009, Cardinaud et al., 2014).

Unfortunately, despite its pathogenicity, the lack of genetic tools for environmental Vibrio strains like $V$. harveyi ORM4 hampers a better understanding of the infection mechanisms. Moreover, genetic tools to introduce exogenous DNA (either as replicative plasmids or as mini-transposons) are available for the type strain V. campbellii BAA-1116, but they almost exclusively rely on conjugation, using plasmid-bearing Escherichia coli strains. Conjugation is a powerful mean to genetically manipulate bacteria, but this system is time consuming, requiring typically 4-5 days including the inoculation of strains, the mating on plates and the selection of potential transformants. Moreover, the counter-selection of the E. coli donor cells can also be challenging. Therefore, alternatives to conjugations are necessary to introduce foreign DNA in $V$. harveyi strains.

In this study, we developed an electroporation protocol to introduce replicative plasmids and mini-transposons in $V$. harveyi ORM4. As a proof, we introduced a bioreporter in this strain to follow the expression of a flagellum promoter. Finally, we extended this 
protocol to $V$. harveyi strain LMG7890 and V. campbellii BAA-1116, as well as to bacterial strains outside the Vibrionales order and belonging to the genus Pseudoaltermonas.

\section{Materials and Methods}

\subsection{Bacterial strains and growth conditions}

Unless otherwise stated, E. coli strains were routinely grown at $37{ }^{\circ} \mathrm{C}$ in LB, $V$. harveyi strains at $28^{\circ} \mathrm{C}$ in LB supplemented with $20 \mathrm{~g} / 1$ (final concentration, f.c.) $\mathrm{NaCl}$ (LBS) and Pseudoalteromonas strains at $20{ }^{\circ} \mathrm{C}$ in MLB $(15 \mathrm{~g} / \mathrm{l}$ sea salt, $10 \mathrm{~g} / \mathrm{l}$ peptone and $5 \mathrm{~g} / \mathrm{l}$ yeast extract). If necessary, the following antibiotics and components were used: ampicillin $(100 \mu \mathrm{g} / \mathrm{ml})$, kanamycin $(100 \mu \mathrm{g} / \mathrm{ml}$ for E. coli, $250 \mu \mathrm{g} / \mathrm{ml}$ for $V$. harveyi $)$, chloramphenicol $(5 \mu \mathrm{g} / \mathrm{ml})$, trimethoprim $(10 \mu \mathrm{g} / \mathrm{ml})$, diaminopimelic acid (DAP, $0.3 \mathrm{mM}$ ) and agar $15 \mathrm{~g} / \mathrm{l}$. The list of strains and plasmids used in this study can be found in Table 1.

\subsection{Construction of the pTNS3-derivative plasmids}

The minimal origin of replication of pES213 (Dunn et al., 2005), amplified using primers

5'TTTTTTGCATGCACGCGTATCGATCTCGAGAACTATCAATAGAACGTGTATTTA 3' and ${ }^{5}$ 'TTTTTTGTCGACGCAGCTCTTAATATTTTCTTTTT ${ }^{3}$ ', was cloned into pTNS3 (Choi et al., 2008) between the SphI and SalI sites, creating pFD051. The chloramphenicol resistance gene was amplified from pVSV208 (Dunn et al., 2006) using 5' ${ }^{\prime}$ TTTTTGCATGCGTGTTATGAGCCATATTCAAC ${ }^{3}$ ' and 5'TTTTTTCTCGAGCAATAACTGCCTTAAAAAAATTAC ${ }^{3}$, , cloned in pFD051 using SphI + XhoI, creating pFD052. The kanamycin resistance gene was amplified from pVSV102 (Dunn et al., 2006) using 5'TTTTTTGCATGCGGGGTGCCTAATGAGTGAG ${ }^{3}$ ' and 5'TTTTTACGCGTGCTCTGCCAGTGTTACAAC ${ }^{3}$ ', cloned in pFD051 using SphI + MluI, creating pFD061.

\subsection{Construction of the bioreporters}

The $\mathrm{P}_{f l g F G H}$ promoter of the flgFGH operon of $V$. harveyi ORM4 (unpublished genome) was amplified using ${ }^{5}$ 'TTTTTTCTAGAGCTACAACAAAATATCCTGC ${ }^{3}$ ' and 5'TTTTTGTCGACGCTCATTGCGAGAAACAGTG ${ }^{3}$ ' and cloned in pJLS199 using XbaI + 
SalI, creating pFD058. The Plac promoter was digested from pVSV102 (Dunn et al., 2006) using XhoI + NheI and cloned into pJLS199 using the same enzymes, creating pFD063.

\subsection{Electroporation protocol}

V. harveyi and Pseudoalteromonas strains were grown overnight at $37{ }^{\circ} \mathrm{C}$ and $24{ }^{\circ} \mathrm{C}$, respectively. Overnight cultures were placed on ice and $2 \mathrm{ml}$ aliquots were washed 3 times with $1 \mathrm{ml}$ of an ice-cold modified sucrose buffer (Visick \& Ruby, 1996), containing $272 \mathrm{mM}$ sucrose, $1 \mathrm{mM} \mathrm{MgCl}, 7 \mathrm{mM} \mathrm{K}_{2} \mathrm{HPO}_{4}$ adjusted to $\mathrm{pH} 7.5$ and sterilized by autoclaving. Immediately before use, $15 \%$ glycerol (f.c.) was added to the buffer to avoid cell lysis. After 3 washing steps, electrocompetent cells were concentrated in $50 \mu \mathrm{l}$ with the same buffer and placed in an ice-cold $1 \mathrm{~mm}$ electroporation cuvette, mixed with plasmid DNA and directly electroporated with a Gene Pulser II + Pulse Controller Plus (Biorad) set at $1.5 \mathrm{kV}, 200 \Omega$ resistance and $25 \mu \mathrm{F}$ capacitance. Immediately after electroporation, $1 \mathrm{ml}$ LBS for $V$. harveyi or MLB for Pseudoalteromonas was added, and cells were allowed to recover for $4 \mathrm{~h}$ at $37^{\circ} \mathrm{C}$ or $24^{\circ} \mathrm{C}$ for $V$. harveyi and Pseudoalteromonas, respectively. Cell suspensions were then plated on selective plates and incubated overnight at $28^{\circ} \mathrm{C}$ for $V$. harveyi and for 2-3 days at $20{ }^{\circ} \mathrm{C}$ for Pseudoalteromonas.

\subsection{Microscopy experiments}

One colony of pFD058- or pFD063-bearing strains of $V$. harveyi ORM4 was inoculated in $5 \mathrm{ml} \mathrm{LBS+Trim.} 100 \mu \mathrm{l}$ of each overnight suspension were used to inoculate 5 $\mathrm{ml}$ LBS+Trim. Microscopy was performed after overnight growth and after $2 \mathrm{~h}, 4 \mathrm{~h}$ and $6 \mathrm{~h}$ of growth, in triplicates. Images were acquired using the Zeiss Axio Imager.M2 microscope equipped with a 63X Apochromat oil objective, at $200 \mathrm{~ms}$ exposure time for GFP (with 10\% and 100\% LED intensity, for pFD063 and pFD058, respectively). Images were analysed using an in-house written Matlab script, with at least 1000 cells per replicate (Delavat et al., 2016).

\section{Results and discussion}

\subsection{An electroporation method to transform V. harveyi and Pseudoalteromonas strains}

A one-day-long electroporation protocol was sufficient to obtain several hundreds of trimethoprim-resistant colonies of $V$. harveyi ORM4 when transformed with pFD063. 
Efficient electroporation was obtained when using overnight cultures of $V$. harveyi ORM4 grown at $37^{\circ} \mathrm{C}$, while no transformant was obtained when cells were grown at $28^{\circ} \mathrm{C}$ or when using exponentially-growing cells at $37^{\circ} \mathrm{C}$ (Table 2). Presence of the plasmid in all tested colonies of $V$. harveyi ORM4 was confirmed by colony-PCR verification (at least 8 colonies tested per electroporation, at least 5 independent experiments performed) and by a bright green colour of the colony (Figure 1A). This temperature-dependent electroporation efficiency might be surprising, but it is supposed that cells grown under supra-optimal temperature $\left(37^{\circ} \mathrm{C}\right.$ instead of $\left.28^{\circ} \mathrm{C}\right)$ have an altered restriction-modification system, making them more prone to accept foreign DNA, as demonstrated for Pseudomonas aeruginosa (Rolfe \& Holloway, 1969).

Typically, 200 ng of plasmid DNA were sufficient to obtain at least 300-400 colonies, i.e. to get a transformation efficiency of at least $1.5 \times 10^{3} \mathrm{CFU} / \mu \mathrm{g}$ DNA. Moreover, the number of CFUs obtained was in the same range when using as low as $50 \mathrm{ng}$ of plasmid DNA (transformation efficiency of $9 \times 10^{2}$ s.d $2.5 \times 10^{2} \mathrm{CFU} / \mu \mathrm{g}$ DNA), giving the possibility to transform low-copy number plasmids. pFD063 is a rather small plasmid (4.8 kb) but successful electroporation was also obtained with the $6.5 \mathrm{~kb}$-long pVSV208 (Dunn et al.,

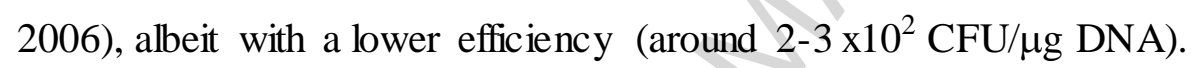

In addition, the washing buffer used to prepare competent cells contains $15 \%$ glycerol (f.c.), allowing competent-cells to be flash-frozen in liquid nitrogen and stored at $-80^{\circ} \mathrm{C}$ until further use. Cells retain full transformability after having been stored for at least one month at $-80^{\circ} \mathrm{C}$, with several hundreds of CFUs obtained with $200 \mathrm{ng}$ of pFD063 (transformation efficiency of at least $6 \times 10^{3} \mathrm{CFU} / \mu \mathrm{g}$ DNA).

Using the exact same protocol as for $V$. harveyi ORM4, we could also transform by electroporation $V$. harveyi LMG 7890, isolated from a dead brown shark kidney, with $200 \mathrm{ng}$ of the pFD063 plasmid DNA. This resulted in hundreds of pFD063-bearing colonies of $V$. harveyi LMG 7890 obtained within one single day (electroporation efficiency between 1.5 and $6 \times 10^{3} \mathrm{CFU} / \mu \mathrm{g}$ DNA). In addition, the type strain $V$. campbellii BAA-1116 could also be transformed using the exact same protocol, with an electroporation efficiency reaching $2.7 \times 10^{2}$ CFU/ $\mu$ g DNA s.d. $1.3 \times 10^{2}$ ). Finally, we applied our protocol on four Pseudoalteromonas sp. strains, namely Pseudoalteromonas sp. PV1, Pseudoalteromonas sp. MV21, Pseudoalteromonas sp. 3J3 and Pseudoalteromonas sp. 3J6, using the $6.8 \mathrm{~kb}$-long pOriT-4Em (Yu et al., 2014) plasmid. Under these conditions, between 50 and 60 ampicillinresistant and pOriT-4Em-bearing colonies of Pseudoalteromonas sp. MV21 and 3J6 were 
obtained (at least $1.25 \times 10^{2} \mathrm{CFU} / \mu \mathrm{g}$ DNA), while no transformant was obtained for Pseudoalteromonas sp. PV1 and 3J3.

Thus, we developed an efficient electroporation method to obtain transformants of $V$. harveyi and Pseudoalteromonas strains within one day, with as low as $50 \mathrm{ng}$ of plasmid DNA and with the possibility to store competent cells for future use. We expect this protocol to be easily adapted to other marine environmental strains with a few modifications, presumably at the growing and recovering temperatures used.

\subsection{Phenotypic heterogeneity associated with gene expression in V. harveyi ORM4}

Replicative plasmids are useful tools for different purposes, e.g. in genetics for gene complementation and overexpression or in molecular and synthetic biology to construct bioreporters. Bioreporters are molecular systems engineered to follow and monitor gene expression at the single-cell or population-wide levels. Typically, a bioreporter is a circuit composed of two parts, i.e. a reporter gene (e.g. gfp or $\beta$-gal), itself being transcriptionally fused to a promoter whose expression is studied. Fluorescent bioreporters are of particular interest, because their activity can be quantified in real time and at the single-cell level, without the need of external substrates.

A bacterial bioreporter held on a plasmid was constructed, by cloning in E. coli the promoter of the flgFGH operon of $V$. harveyi ORM4 (unpublished genome) into the pJLS199 plasmid, upstream of the promoterless $g f p$ gene. The resulting plasmid pFD058 was transformed back into $V$, harveyi ORM4 by electroporation, and successful introduction of pFD058 in V. harveyi ORM4 was confirmed by colony-PCR. Expression of the $\mathrm{P}_{f l g F G H^{-}} g f p$ bioreporter was measured in single cells of $V$. harveyi ORM4-pFD058 when grown from exponential phase to stationary phase. Interestingly, while expression from the $\mathrm{P}_{f l g F G H}$ promoter in $V$. harveyi ORM4 is rather homogeneous during exponential phase, only $9.9 \%$ (s.d. 1.6\%) of the cells from this isogenic population strongly express this promoter during stationary phase (Figure 1B, white arrow). This bimodal distribution of gene expression is specific to $\mathrm{P}_{f l g F G H}$, since cells of $V$. harveyi ORM4 carrying a similar bioreporter in which the gfp gene is under the control of the constitutive $\mathrm{P}_{l a c}$ promoter behave generally similarly, whatever the condition (between 95 and $99.7 \%$ of the population, Figure 1B). In order to rule out a possible loss of pFD058, $V$. harveyi ORM4-pFD058 grown to stationary phase in LBS+Trim were plated on LBS without antibiotic and then restreaked both on LBS and LBS containing trimethoprim. All of the tested colonies ( 3 replicates, $n=106$ ) were still 
trimethoprim-resistant and contained the pFD058 plasmid. Moreover, the stability of pJLS199-derived plasmids in the absence of selective pressure was quantified by measuring the proportion of cells still bearing pFD058 after circa 40 generations. Under this nonselective condition, $94 \%$ (s.d. 10\%) still carried the plasmid, highlighting its good stability and confirming the bimodal gene expression from the $\mathrm{P}_{f l g F G H}$ promoter in $V$. harveyi ORM4 grown to stationary phase.

Phenotypic heterogeneity in bacterial gene expression has been observed in many bacterial processes, e.g. for spore formation or competence in Bacillus subtilis, during horizontal gene transfer of integrative and conjugative elements (Delavat et al., 2017) or in genes controlled by the quorum sensing system of $V$. campbellii BAA-1116 (Anetzberger et $a l ., 2012)$. In addition, flagellum expression is known to be prone to phenotypic noise, as discovered in Salmonella enterica ssp. I serovar Typhimurium (Freed et al., 2008). However, to our knowledge, nothing is known about the phenotypic heterogeneity associated with flagellum expression in any V. harveyi strain nor in any other strain from the genus Vibrio.

\subsection{Chromosomal insertion of a mini-transposon}

While replicative plasmids are useful tools to rapidly introduce foreign DNA, it is sometimes important to stably introduce foreign DNA in chromosomes and express it from a single copy. This is typically achieved by the insertion of mini-transposons. Mini- $T n 7$ transposons insert site-specifically at the 3' end of the $\operatorname{glmS}$ gene of many Gram-negative bacteria, ruling out insertions in important genes biasing the phenotype of the resulting mutant (Choi et al., 2005). In a first attempt, we sought to use the existing mini- $\operatorname{Tn} 7$ delivery system, composed of a strain carrying the transposase-encoding pTNS3 plasmid (Choi et al., 2008) and a strain carrying the pUC-miniTn7T-Km plasmid. Tri-parental mating was performed by mixing these strains with $V$. harveyi ORM4. Kanamycin-resistant clones of $V$. harveyi ORM4 containing the mini-Tn7T were obtained under this condition. However, none of them carried a mini-Tn7T integrated at the 3' of $\operatorname{glm} S$. Moreover, colony-PCR on the obtained clones demonstrated the presence of the pUC backbone plasmid (data not shown). As pUCderivative plasmids cannot be stably maintained as episomes in Vibrio species, it is likely that the entire pUC-mini-Tn7T-Km plasmid has inserted somewhere in the genome by homologous recombination.

We hypothesized that the limiting factor of transposition was the transient expression of the transposase from pTNS3. To test this hypothesis, the smallest fragment containing the 
origin of replication from the pES213 (Dunn et al., 2005) and a chloramphenicol-resistance gene were cloned into pTNS3. The resulting plasmid (pFD052) was introduced in $V$. harveyi ORM4 by tri-parental mating, and chloramphenicol-resistant colonies of $V$. harveyi ORM4 were obtained. Presence of the pFD052 plasmid was confirmed by colony-PCR. Bi-parental mating between $V$. harveyi ORM4 and $E$. coli carrying the pUC-mini-Tn7T-Km plasmid was performed, and all $V$. harveyi ORM4 transconjugants obtained on LBS+kanamycin contained the mini-Tn7T-Km transposon. Moreover, the mini-Tn7T-Km transposon was inserted in 7 out of the 8 tested clones at the 3' end of the $\operatorname{glm} S$ gene. 5 of those clones were randomly chosen for a southern blotting experiment, which confirmed that insertion occurred at a single location within the entire genome of $V$. harveyi ORM4 (data not shown). Finally, an overnight growth of one positive clone in LBS+Km without chloramphenicol was sufficient to cure out the pFD052 plasmid in all of the tested colonies $(n=64)$.

We next replaced the chloramphenicol-resistance gene in pFD052 by the kanamycinresistance gene, and the resulting plasmid (pFD061) was again introduced by tri-parental mating in $V$. harveyi ORM4. Electrocompetent cells of the resulting strain were then prepared and transformed with the pUC-mini-Tn7T-Cm plasmid. Cm-resistant clones were obtained, and most of them had the mini-Tn7T-Cm transposon inserted at the 3' of the $\operatorname{glm} S$ site. By contrast, clones obtained by electroporation of $V$. harveyi ORM4 with both pTNS3 and pUCmini-Tn7T-Cm did not give any transformant on $\mathrm{LBS}+\mathrm{Cm}$ plates.

We were therefore able to improve the mini- $T n 7$ delivery system by the creation of an unstable transposase-producing replicative plasmid for Vibrio species, allowing introduction of mini- $T n 7 \mathrm{~T}$ transposons, both by conjugation and electroporation.

To conclude, we developed an electroporation protocol enabling the introduction of replicative plasmids (and GFP-labelling) in various V. harveyi and Pseudoalteromonas strains, and improved the mini-Tn7 delivery system to allow mini-transposon insertions in single copy in the genome of $V$. harveyi ORM4. Moreover, we demonstrated for the first time in Vibrio that gene expression from a flagellum promoter is restricted to a subpopulation of the isogenic cell population, highlighting the occurrence of phenotypic heterogeneity in this pathogenic strain for this particular trait. It remains to be discovered whether this phenotypic heterogeneity plays a role in the virulence of this economically important bacterium.

\section{Acknowledgments}


This work was supported by the "Laboratoire d'Excellence" LabexMER (ANR-10LABX-19) and co-funded by a grant from the French government under the program "Investissements d'Avenir", and by a grant from the Regional Council of Brittany. This project received grants from the H2020 VIVALDI project (grant agreement $n^{\circ} 678589$ ). The authors would like to thank Pr. Eric Stabb and Julie Lynn Stoudenmire (University of Georgia) for the gift of the pJLS199, pVSV102 and pVSV208 plasmids, Pr. Masataka Tsuda (Tohoku University, Japan) for providing the pUC18-miniTn7T-Km plasmid and Dr. Alexis Bazire and Pr. Alain Dufour (University of Southern Brittany, France) for the Pseudoalteromonas strains. The authors are grateful to Loeiz Maillet for his help in the development of the electroporation procedure in V. harveyi ORM4 and to Rémi Dulermo (University of Western Brittany, France) for his help for the Southern Blotting experiment.

\section{Legend to Figure 1.}

Images resulting from electroporations of plasmids in $V$. harveyi ORM4. (A), Plate obtained after electroporation of $V$. harveyi ORM4 with pFD063. Note the green colour of the colonies. (B), microscopy images (x630 magnification) of the bioreporters. On the left, bioreporter expression from the $\mathrm{P}_{f l g F G H}$ promoter. On the right, bioreporter expression from the $\mathrm{P}_{\text {lac }}$ promoter. Note that only a fraction (white arrow) of the population is expressing GFP from the $\mathrm{P}_{\text {flgFGH }}$ promoter, while expression from $\mathrm{P}_{\text {lac }}$ is more homogeneous. 
Table 1. Strains and plasmids used in this study

\begin{tabular}{|c|c|c|}
\hline Strain or plasmid & Relevant characteristics & $\begin{array}{l}\text { Source or } \\
\text { reference }\end{array}$ \\
\hline \multicolumn{3}{|l|}{ Strains } \\
\hline E. coliDH5 $\alpha-\lambda$ pir & $\begin{array}{c}\text { supE44 Dlacu169 (f80 lacZDM15) hsdR17 } \\
\text { recA1 endA1 gyrA96 thi-1 relA1 }\end{array}$ & Lab strain \\
\hline V. harveyi ORM4 & $\begin{array}{l}\text { Virulent strain infecting the European abalone } \\
\text { Haliotis tuberculata }\end{array}$ & $\begin{array}{l}\text { (Nicolas et } \\
\text { al., 2002) }\end{array}$ \\
\hline V. harveyi LMG 7890 & $\begin{array}{l}\text { Avirulent strain of } V \text {. harveyi isolated from the } \\
\text { kidney of a dead brown shark }\end{array}$ & $\begin{array}{l}\text { (Grimes et } \\
\text { al., 1984) }\end{array}$ \\
\hline $\begin{array}{r}\text { V. campbelliiBAA- } \\
1116\end{array}$ & $\begin{array}{c}\text { Type strain of } V \text {. harveyi, recently reclassified as } \\
\text { Vibrio campbellii }\end{array}$ & $\begin{array}{l}\text { (Bassler et } \\
\text { al., 1997) }\end{array}$ \\
\hline $\begin{array}{r}\text { Pseudoalteromonas } \\
\text { sp. PV1 }\end{array}$ & $\begin{array}{c}\begin{array}{c}\text { Strain of Pseudoalteromonas isolated from the } \\
\text { indian ocean }\end{array} \\
\text {. }\end{array}$ & $\begin{array}{l}\text { Gift from } \\
\text { Dr. Alexis } \\
\text { Bazire }\end{array}$ \\
\hline $\begin{array}{r}\text { Pseudoalteromonas } \\
\text { sp. MV21 }\end{array}$ & $\begin{array}{c}\text { Strain of Pseudoalteromonas isolated from the } \\
\text { indian ocean }\end{array}$ & $\begin{array}{l}\text { Gift from } \\
\text { Dr. Alexis } \\
\text { Bazire }\end{array}$ \\
\hline $\begin{array}{r}\text { Pseudoalteromonas } \\
\text { sp. 3J3 }\end{array}$ & $\begin{array}{l}\text { Strain isolated from a glass slide immersed in } \\
\text { seawater }\end{array}$ & $\begin{array}{l}\text { (Grasland } \\
\text { et al., } \\
2003)\end{array}$ \\
\hline $\begin{array}{r}\text { Pseudoalteromonas } \\
\text { sp. 3J6 }\end{array}$ & $\begin{array}{c}\text { Strain isolated from a glass slide immersed in } \\
\text { seawater }\end{array}$ & $\begin{array}{l}\text { (Grasland } \\
\text { et al., } \\
2003)\end{array}$ \\
\hline Plasmids & 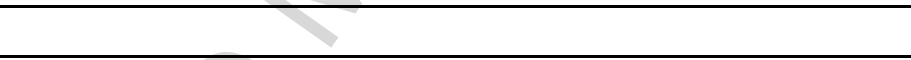 & \\
\hline pJLS199 & $\begin{array}{c}\text { Replicative plasmid for Vibrio (ori pES213). } \\
\text { Similar to pJLS198 (Stoudenmire et al., 2018) } \\
\text { except the gfp gene encodes the original stable } \\
\text { GFP variant used in that study. Trim }\end{array}$ & $\begin{array}{l}\text { Gift from } \\
\text { Pr. E. } \\
\text { Stabb }\end{array}$ \\
\hline pTNS3 & $\begin{array}{l}\text { Replicative plasmid for } E \text {. coli. Expresses } \\
\text { tns } A B C D \text { from } P / \text { and lac promoters. Allows } \mathrm{Tn} 7 \\
\text { insertions at the } g / m S \text { site. Ap }\end{array}$ & $\begin{array}{l}\text { (Choi et } \\
\text { al., 2008) }\end{array}$ \\
\hline pFD051 & $\begin{array}{c}\text { Derivative of pTNS3 carrying the minimal origin } \\
\text { of replication from pEVS213. Replicates in } \\
\text { Vibrio species. Ap }\end{array}$ & This study \\
\hline pFD052 & $\begin{array}{l}\text { Derivative of pFD051 carrying a } \\
\text { chloramphenicol resistance gene. } \mathrm{Ap}^{\mathrm{R}}, \mathrm{Cm}^{\mathrm{R}}\end{array}$ & This study \\
\hline pFD058 & $\begin{array}{c}\text { Derivative of pJLS199 carrying the } \mathrm{P}_{\text {flgFGH }} \\
\text { promoter of } V \text {. harveyi ORM4 cloned upstream } \\
\text { of the gfp gene. Trim }{ }^{R}\end{array}$ & This study \\
\hline pFD061 & $\begin{array}{l}\text { Derivative of pFD051 carrying a kanamycin } \\
\text { resistance gene. } \mathrm{Ap}^{\mathrm{R}}, \mathrm{Km}^{\mathrm{R}}\end{array}$ & This study \\
\hline pFD063 & $\begin{array}{c}\text { Derivative of pJLS199 carrying the } P_{\text {lac }} \text { promoter } \\
\text { from pVSV102 cloned upstream of the gfp gene. } \\
\text { Trim }^{R}\end{array}$ & This study \\
\hline pFD066 & $\begin{array}{c}\text { Derivative of pUC18-mini Tn7T-Gm (AY599231) } \\
\text { containing the Chloramphenicol resistance } \\
\text { gene. } \mathrm{Ap}^{\mathrm{R}}, \mathrm{Cm}^{\mathrm{R}}\end{array}$ & This study \\
\hline
\end{tabular}




\begin{tabular}{|r|c|c|}
\hline pUC18-miniTn7T-Km & $\begin{array}{c}\text { Derivative of pUC18-mini Tn7T-Gm (AY599231) } \\
\text { containing the kanamycin resistance gene. Ap } \\
\mathrm{Km}^{\mathrm{R}}\end{array}$ & $\begin{array}{c}\text { Gift from } \\
\text { the } \\
\text { Masataka } \\
\text { Tsuda lab }\end{array}$ \\
\hline pOriT-4Em & $\begin{array}{c}\text { Replicative plasmid for Pseudoalteromonas } \\
\text { species. Ap }{ }^{\mathrm{R}}, \mathrm{Em}^{\mathrm{R}}\end{array}$ & $\begin{array}{c}\text { Yu et al., } \\
2014)\end{array}$ \\
\hline
\end{tabular}

Table 2. Electroporation conditions used in this study

\begin{tabular}{|c|c|c|c|}
\hline Strain & $\begin{array}{l}\text { Plasmid used for } \\
\text { electroporation }\end{array}$ & $\begin{array}{l}\text { Condition of } \\
\text { Electroporation }\end{array}$ & $\begin{array}{l}\text { Electroporation } \\
\text { efficiency }(\mathrm{CFU} / \mu \mathrm{g} \\
\text { DNA) }\end{array}$ \\
\hline V. harveyi ORM4 & pFD063 (4.8 kb) & $\begin{array}{l}\text { Stationary-phase } \\
\text { cells grown at } 28^{\circ} \mathrm{C}\end{array}$ & No transformant \\
\hline V. harveyi ORM4 & pFD063 (4.8 kb) & $\begin{array}{l}\text { Exponentially- } \\
\text { growing cells at } \\
37^{\circ} \mathrm{C}\end{array}$ & No transformant \\
\hline V. harveyi ORM4 & pFD063 (4.8 kb) & $\begin{array}{l}\text { Stationary-phase } \\
\text { cells grown at } 37^{\circ} \mathrm{C}\end{array}$ & $1.5 \times 10^{3}$ to $6 \times 10^{3}$ \\
\hline V. harveyi ORM4 & pVSV208 $(6.5 \mathrm{~kb}$ & $\begin{array}{l}\text { Stationary-phase } \\
\text { cells grown at } 37^{\circ} \mathrm{C}\end{array}$ & $2-3 \times 10^{2}$ \\
\hline $\begin{array}{l}\text { V. harveyi LMG } \\
7890\end{array}$ & pFD063 (4.8 kb) & $\begin{array}{l}\text { Stationary-phase } \\
\text { cells grown at } 37^{\circ} \mathrm{C}\end{array}$ & $1.5 \times 10^{3}$ to $6 \times 10^{3}$ \\
\hline $\begin{array}{l}\text { V. campbellii BAA- } \\
1116\end{array}$ & pFD063 (4.8 kb) & $\begin{array}{l}\text { Stationary-phase } \\
\text { cells grown at } 37^{\circ} \mathrm{C}\end{array}$ & $2.7 \times 10^{2}$ \\
\hline $\begin{array}{l}\text { Pseudoalteromonas } \\
\text { sp. PV1 }\end{array}$ & pOriT-4Em (6.8 kb) & $\begin{array}{l}\text { Stationary-phase } \\
\text { cells grown at } 24^{\circ} \mathrm{C}\end{array}$ & No transformant \\
\hline $\begin{array}{l}\text { Pseudoalteromonas } \\
\text { sp. MV21 }\end{array}$ & pOriT-4Em $(6.8 \mathrm{~kb})$ & $\begin{array}{l}\text { Stationary-phase } \\
\text { cells grown at } 24^{\circ} \mathrm{C}\end{array}$ & $1.25 \times 10^{2}$ \\
\hline $\begin{array}{l}\text { Pseudoalteromonas } \\
\text { sp. } 3 \mathrm{~J} 3\end{array}$ & pOriT-4Em (6.8 kb) & $\begin{array}{l}\text { Stationary-phase } \\
\text { cells grown at } 24^{\circ} \mathrm{C}\end{array}$ & No transformant \\
\hline $\begin{array}{l}\text { Pseudoalteromonas } \\
\text { sp. 3J6 }\end{array}$ & pOriT-4Em $(6.8 \mathrm{~kb})$ & $\begin{array}{l}\text { Stationary-phase } \\
\text { cells grown at } 24^{\circ} \mathrm{C}\end{array}$ & $1.25 \times 10^{2}$ \\
\hline
\end{tabular}

\section{Conflict of interest}

The authors declare that they have no competing interests. 


\section{References}

Anetzberger C, Schell U \& Jung K (2012) Single cell analysis of Vibrio harveyi uncovers functional heterogeneity in response to quorum sensing signals. Bmc Microbiology 12. Austin B \& Zhang XH (2006) Vibrio harveyi: a significant pathogen of marine vertebrates and invertebrates. Letters in Applied Microbiology 43: 119-124.

Bassler BL, Greenberg EP \& Stevens AM (1997) Cross-species induction of luminescence in the quorum-sensing bacterium Vibrio harveyi. Journal of Bacteriology 179: 40434045.

Cardinaud M, Offret C, Huchette S, Moraga D \& Paillard C (2014) The impacts of handling and air exposure on immune parameters, gene expression, and susceptibility to vibriosis of European abalone Haliotis tuberculata. Fish Shellfish Immunol 36: 1-8.

Choi KH, Gaynor JB, White KG, Lopez C, Bosio CM, Karkhoff-Schweizer RR \& Schweizer HP (2005) A Tn7-based broad-range bacterial cloning and expression system. Nature Methods 2: 443-448.

Choi KH, Mima T, Casart Y, Rholl D, Kumar A, Beacham IR \& Schweizer HP (2008) Genetic tools for select-agent-compliant manipulation of Burkholderia pseudomallei. Applied and Environmental Microbiology 74: 1064-1075.

Delavat F, Mitri S, Pelet S \& van der Meer JR (2016) Highly variable individual donor cell fates characterize robust horizontal gene transfer of an integrative and conjugative element. Proceedings of the National Academy of Sciences of the United States of America 113: E3375-E3383.

Delavat F, Miyazaki R, Carraro N, Pradervand N \& van der Meer JR (2017) The hidden life of integrative and conjugative elements. FEMS Microbiology Reviews 41: 512-537.

Dunn AK, Martin MO \& Stabb EV (2005) Characterization of pES213, a small mobilizable plasmid from Vibrio fischeri. Plasmid 54: 114-134.

Dunn AK, Millikan DS, Adin DM, Bose JL \& Stabb EV (2006) New rfp- and pES213derived tools for analyzing symbiotic Vibrio fischeri reveal patterns of infection and lux expression in situ. Applied and Environmental Microbiology 72: 802-810.

Freed NE, Silander OK, Stecher B, Bohm A, Hardt WD \& Ackermann M (2008) A simple screen to identify promoters conferring high levels of phenotypic noise. Plos Genetics 4.

Grasland B, Mitalane J, Briandet R, Quemener E, Meylheuc T, Linossier I, Vallee-Rehel K \& Haras D (2003) Bacterial biofilm in seawater: Cell surface properties of early-attached marine bacteria. Biofouling 19: 307-313.

Grimes DJ, Stemmler J, Hada H, May EB, Maneval D, Hetrick FM, Jones RT, Stoskopf M \& Colwell RR (1984) Vibrio species associated with mortality of sharks held in captivity. Microbial Ecology 10: 271-282.

Lin BC, Wang Z, Malanoski AP, O'Grady EA, Wimpee CF, Vuddhakul V, Alves N, Thompson FL, Gomez-Gil B \& Vora GJ (2010) Comparative genomic analyses identify the Vibrio harveyi genome sequenced strains BAA-1116 and HY01 as Vibrio campbellii. Env Microbiol Rep 2: 81-89.

Nicolas JL, Basuyaux O, Mazurie J \& Thebault A (2002) Vibrio carchariae, a pathogen of the abalone Haliotis tuberculata. Dis Aquat Organ 50: 35-43.

Plener L, Lorenz N, Reiger M, Ramalho T, Gerland U \& Jung K (2015) The phosphorylation flow of the Vibrio harveyi quorum-sensing cascade determines levels of phenotypic heterogeneity in the population. Journal of Bacteriology 197: 1747-1756.

Rolfe B \& Holloway BW (1969) Host specificity of DNA and conjugation in Pseudomonas aeruginosa. Genetics 61: 341-\&. 
Stoudenmire JL, Essock-Burns T, Weathers EN, Solaimanpour S, Mrazek J \& Stabb EV (2018) An iterative synthetic approach to engineer a high-performing PhoB-specific reporter. Appl Environ Microbiol.

Travers MA, Basuyaux O, Le Goic N, Huchette S, Nicolas JL, Koken M \& Paillard C (2009) Influence of temperature and spawning effort on Haliotis tuberculata mortalities caused by Vibrio harveyi: an example of emerging vibriosis linked to global warming. Global Change Biol 15: 1365-1376.

Visick KG \& Ruby EG (1996) Construction and symbiotic competence of a luxA-deletion mutant of Vibrio fischeri. Gene 175: 89-94.

Yu ZC, Zhao DL, Ran LY, et al. (2014) Development of a genetic system for the deep-sea psychrophilic bacterium Pseudoalteromonas sp SM9913. Microbial Cell Factories 13. 
Development of an electroporation protocol for Vibrio harveyi and Pseudoalteromonas

$>$ New genetic tool for the insertion of mini-Tn7 transposons in $V$. harveyi

$>$ A flagellum promoter of $V$. harveyi is subjected to phenotypic heterogeneity 